\title{
Chapter 40 \\ MODEL TESTS ON THE MOTION \\ OF MOORED SHIPS PLACED ON LONG WAVES
}

\author{
F.A. Kilner \\ Senior Scientific Officer, Hyaraulics Research Station, \\ Wallingford, Berks, England.
}

\begin{abstract}
.
The equation of motion for a moored ship, subject to stationary wave action, is presented and discussed. The moorings are longitudinal, the ship is considered to be aligned to the direction of wave motion and positioned at a node, and the wave length is assumed long compared with the ship length. If the motion of the ship is assumed to be simple harmonic, and frictional forces between the ship and the water are neglected, an elementary analysis gives the required relation between the amplitudes of the ship's movement and of the water particle motion associated with the wave. A description is given of some tests carried out on model ships moored in a flume where stationary waves can be generated, and the amplitude and period can be varied independently. In these experiments, the amplitude of ship movement could be measured visually, or inferred from strain gauge readings, and the water motion was also observed. The results of these tests are compared with the simple theory. A table tilting harmonically is shown to be a mechanical analogy to stationary wave action on ships. The hydrodynamic mass for a ship moving in surge or sway motion is measured and is found to depend on the depth of water in which the ship is moored.
\end{abstract}

\section{INTRODUCTION}

The response of moored ships to long waves was first considered in detail by Wilson 1 in connection with an investigation of Cape Town harbour. Subsequent paperg have been published on variolis aspects of the problem, notably Knapp ${ }^{2}$, Abramson and Wilson 3 , Russell 4 , Joosting 5 , Wiegel et alia ${ }^{6} 7,0^{\prime B r i e n}$ and Kuchenreuther ${ }^{8}{ }^{\prime} 9$, Russeli 10 and Wiegel et alia ${ }^{11}$, in chronological order. There is, however, little published information in which the theory of motion of moored ships is compared with model or field measurements, and this absence is regrettable as there seems to be a difference of opinion concerning the relevant equation of motion, the earlier Wilson ${ }^{1}$ version differing, for example, in a significant manner from Russell ${ }^{10}$ or Joosting 5 .

Wilson ${ }^{1}$ described tests on model ships, oscillating longitudinally on long waves, but did not publish any results. He also observed both ship and water movements at various berths in Table Bay harbour, and presented the information as amplitudes and periodicities of the component harmonics, but gave no verification that these motions conformed to his general theory of ship motion. A valuable feature of this paper was the detailed consideration given to the characteristics of 


\section{COASTAL ENGINEERING}

typical moorings.

O'Brien and Kuchenreuther' made measurements on a 12,000 ton ship moored at Port Hueneme, California, where the ship motion was predominantly longitudinal. The mooring forces were measured by resistance strain gauges attached to a tube incorporated directly into the cable lines, and the water surface slope was measured by pressure pickups placed at two points on the floor of the harbour basin. When long waves were excited by external sea conditions, the mass acceleration of the ship was calculated (from the measured motion of the ship) and compared with the algebraic sum of the measured rope tensions and wave forces (computed by the elementary theory). The hydrodynamic mass of the ship was neglected and the authors found that actual peak mooring forces were too low (by about $30 \%$ ) to satisfy the basic equation. Wilson pointed out, in the discussion of reference (9), that if a reasonable value of hydrodynamic mass was included, the discrepancy increases, and he suggested that the estimation of the ship movement from the forces in the moorings may have been unreliable owing to the hysteresis effects that are characteristic of mooring line loading. This paper was a notable contribution because of the resource with which the very difficult problem of prototype forces and movements was tackled. However, the investigation was concerned with a particular case, and made no direct contribution to the solution of ship motion in general terms.

The same authors 8 measured the periods of free oscillation for a moored dry dock in the absence of waves; the displacement was 2100 long tons and the site was also at Port Hueneme in California. The moorings were longitudinal, symmetrical and had a non-linear spring characteristic, although the non-linearity was due in this case to the catenary behaviour of the chain 'moorings', as at no time were the dock movements sufficient to elongate the chains. The vessel was given an initial displacement by a tug and the natural periods estimated from the subsequent intervals at which peak forces were recorded by strain gauges placed in the mooring lines. Both longitudinal ("surge") and transverse ("sway") displacements were imposed, and comparisons were made between the measured periods and those computed from the known mass of the dock and the force characteristics of the mooring restraints. Further comparisons were possible from results obtained from a 1:40 scale model of the same dock, tested at the University of California by Wiegel, Clough, Dilley and Williams 6 , although the majority of these tests were for the surge condition only. The first conclusion of this paper was that the three sets of information viz: prototype, model and analytical were reasonably consistent, and that darming and hydrodynamic mass effects were both negligible. It is to be noted that the water was relatively deep, being three to four times the draft of the dock. The authors conceded, however, that the evidence concerning surge motions was the more reliable, as a combination of large damping and small restoring force quickly reduced the sway amplitudes to zero. 


\section{MODEL TESTS ON THE MOTION \\ OF MOORED SHIPS PLACED ON LONG WAVES}

A 1:80 scale model of a landing ship medium of approximately 860 Iong ton displacement was examined for response to progressive wave action in a detailed paper by Wegel, Beebe and Dilley 7 . The prototype dimensions were a length of 200 ft, a beam of $33 \mathrm{ft}$ and a $13 \mathrm{ft}$ draft, and the moorings used were oblique to the ship's longitudinal axis (120) but were symmetrical about this axis, giving twin moorings at bow and stern, four mooring lines in all. Various wave directions were tested, being equivalent to beam, head and quertering seas. The predominant motions of the ship were recorced on cine film from two cameras placed in suitable positions to observe the required components, and in addition the average cable tensions were obtained from strain gauges mounted on cantilevers attached to the moorings. The independent variables were the wave height, wave period, and cable pre-tension. It appeared to be impossible to produce a basic component motion of the ship in pure form, as in all cases coupled motions were present, and the restiltant movement of the ship was complex. This prohibited an analytical solution although the authors presented conclusions about the influence of resonances on the observed motions.

Russell ${ }^{10}$ was concerned with a particularly difficult case of ship motion, namely the transverse displacement of a ship with unsymetrical restraints consisting of relatively stiff fenders as the restoring force away from the jetty, and relatively soft ropes as the mooring force in the opposite direction. The ratio of stiffnesses may be 1000 or more and in the general case there will be some intermediate free travel in which the ship moves freely on the wave. Two sets of tests were described, the first using a model ship in a model harbour, and the second used the stationary wave flume described in this paper with the model ship idealised to a central section only. Experimental results of the ship

dynamics were presented for various combinations of fenders and ropes and were discussed in general terms. However, it was clear from the asymmetrical and irregular motion that this problem was unlikely to be amenable to a theoretical study and none was attempted. The transverse motion of ships was discussed by Wilson, but appears to have escaped attention subsequently; the paper referred to above will no doubt revive interest in this problem.

The most recent publication on this subject is by Wiegel and colleagues 11 , containing a description of experiments on a $1: 86$ scale model of a liberty ship. The mooring system used in the model was similar to that of the prototype in that it included mooring lines at various inclinations to the ship's longitudinal axis, and also camels (or floating fenders). The direction of wave motion in relation to the ship was varied to reproduce the effects of beam, stern, head and quartering seas, and it is perhaps not surprising that the resliltant motior of the ship are very complicated. The authors suggested that the mooring force records they obtained could be used for prediction of prototype forces, provided the ship form and mooring systems do not differ appreciably from the model. They also state that model studies should be used for any specific ship mooring problem. 
Thus there is an apparent gap in the literature of ship oscillations; there are no published results of ships moving under controlled conditions in which theoretical predictions of ship motion can be compared with experimental measurements. This paper makes such comparisons, which are necessary in order to assess the extent to which full-scale ship mooring loads are predictable for known mooring and ship constants. The experiments are restricted to longitudinal motions with symmetrical restraints as this appears to be by far the simplest from the theoretical point of view.

\section{THEORY}

The following section deals essentially with a ship aligned to the direction of wave motion, restrained by longitudinal symmetrical moorings and positioned at a nodal point. In addition, the wave length is assumed long compared with the ship length.

\section{NOTATION}

$$
\text { Let } \begin{aligned}
m_{1} & =\text { mass of a ship } \\
m_{2} & =\text { hydrodynamic mass associater with the ship } \\
M & =\text { virtual mass }=m_{1}+m_{2} \\
s & =\text { displacement of a ship from its central position. } \\
x & =\text { displacement of a water particle from its central positior } \\
K & =\text { a mooring coefficient } \\
C & =\text { a damping coefficient } \\
s_{0} & =\text { ship amplitude }(0.5 \text { of total travel) } \\
x_{0} & =\text { water amplitude }(0.5 \text { of total travel) }
\end{aligned}
$$

Newton's Law gives:

$$
m_{1} \ddot{s}=\Sigma \text { external forces }
$$

where external forces tending to increase $s$ are positive.

The external forces are:-

$F_{1}$, a drag force, which is a water force due to the relative velocity of the water and ship

$F_{2}$, a wave force, which is a water force due to a pressure gradient in the water (manifested by water accelerations in the ship's absence)

$F_{3}$, a force assocjated with hydrodynamic mass, which is a water force due to the diversion and acceleration of the flow around the ship.

$\mathrm{F}_{4}$, a restraint or mooring force 


\section{MODEL TESTS ON THE MOTION \\ OF MOORED SHIPS PLACED ON LONG WAVES}

Now, $F_{1}$ may be written as $+C(\dot{x}-\dot{s})$

$\mathrm{F}_{2}$ is visualised as the weight of the ship tending to slide down the inclined water surface of the wave and is thus independent of the ship's acceleration.

$\therefore F_{2}=m_{1} g \times$ (water surface slope)

$=\mathrm{m}_{1} \ddot{x}$ for long low waves.

$\mathrm{F}_{3}$ is clearly zero if the ship moves exactly with the water

$$
\therefore F_{3}=m_{2}(\ddot{x}-\ddot{s})
$$

Wilson ${ }^{1}$ demonstrated that, due to catenary effects, typical ship moorings will always allow a certain amount of effective free travel about the central position (i.e., negligible restoring force) followed by a rapialy increasing force for further ship displacement. This is illustrated in Fig. (1).

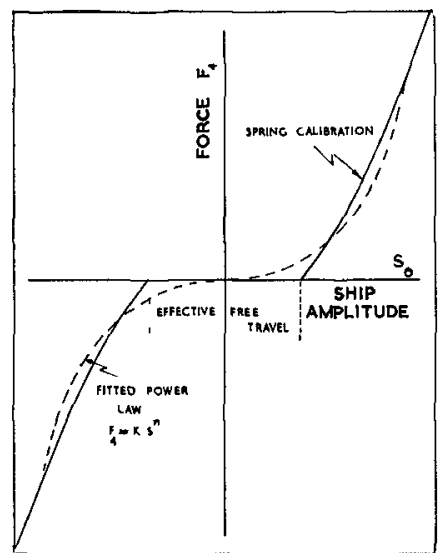

Fig. 1. Spring characteristics of actual and idealized moorings.

Wilson ${ }^{1}$ suggested that this relation could be approximated by a power law of the form:

$F_{4}=K_{s}$

As the physical requirements are such that

$(-s)^{n}=-(s)^{n}$ i.e. $s$ must be an odd function, it follows that $n$ must be a ratio of odd integers, $n=2$, for example, is clearly excluded. The relation $\mathrm{F}_{4}=\mathrm{Ks}^{\mathrm{n}}$ is a mathematically convenient way of representing the restraint of the moorings; it is not the only one, however, $F_{4}=\propto \tan \beta_{s}$ (for example) would also conform to the general shape of the curve in Fig. (1), but would probably be less convenient analytically. The particular case of $\mathrm{n}=1$ represents a linear spring law with no free travel.

Thus equation (1) becomes

$$
\begin{aligned}
& \left(\mathrm{m}_{1}+\mathrm{m}_{2}\right)(\ddot{s}-\ddot{x})+\mathrm{c}(\dot{s}-\dot{x})+K s^{n}=0 \\
& \text { i.e., } \mathrm{M}(\ddot{s}-\ddot{x})+\mathrm{C}(\dot{s}-\dot{x})+\mathrm{Ks}^{\mathrm{n}}=0
\end{aligned}
$$

the case of $\ddot{x}=0$ is proved in "Theoretical Hydrodynamics" by L.M. Milne-Thomson, 2nd edition p.228. The case of $\ddot{x} \neq 0$ does not appear to have been considered mathematically. 


\section{COASTAL ENGINEERING}

Wilson ${ }^{1}$ omitted the wave force from the equation he presented in 1951, and the same error occurs in reference (3). Joosting 5 and Russell ${ }^{10}$ have both presented the equation essentially in the form above and also commented that the drag force is negligible compared with the other terms of the equation, i.e. $\mathrm{C}=0$

Certain special cases can now be examined

(i) static water $\dot{x}=\ddot{x}=0$; also $n=1$; $⿱ 亠 幺 0$

$\therefore$ M:̈̈ $=-K s$

This represents simple harmonic motion of period

$$
\mathrm{T}=2 \pi \sqrt{\frac{\mathrm{M}}{\mathrm{K}}}
$$

This suggests a simple way in which the virtual mass may be determined. A ship is moored with linear springs of known stiffness and no free travel, and the natural period $T$ of oscillation through the water is determined. Then

$$
M=\frac{K T^{2}}{4 \pi}
$$

gives the virtual mass of the ship appropriate to the type of oscillation (Iongitudinal or transverse) from which it was obtained. Damping lengthens the period, but the effect is negligible if $\mathrm{C}^{2}<0.04 \mathrm{MK}$, and $C$ can be estimated from the amplitude decay.

(ii) Stationary ship, $\dot{s}=\ddot{s}=0$

$\therefore$ Force on ship $=M \ddot{x}+C \dot{x}$, a form of equation familiar in studies of wave forces on piles.

(iii) No moorings, $\mathrm{C}=$ ?

$$
\therefore \ddot{s}=\ddot{x}
$$

Thus under suitable release conditions, an unrestrained ship reproduces the motion of the water particles it replaces. This implies that a freely floating body may be used to measure the movement of water in its proximity, which is in fact a familiar concept.

\section{ANAIYSIS}

Accepting the simplification that $\mathrm{C}=0$ the ship motion is governed by equation (2)

$$
M(\ddot{s}-\ddot{x})+K s^{n}=0
$$

Now in a stationary wave of period $2 \pi / \omega$

$$
\begin{aligned}
& x=-x_{0} \sin \omega t \\
& \text { or } \ddot{x}=x_{0} \omega^{2} \sin \omega t \\
& \therefore M \ddot{s}+K s^{n}-M x_{0} \omega_{0}^{2} \sin \omega t=0 \\
& \text { or } \ddot{s}+\frac{K s^{n}}{M}-x_{0} \omega^{2} \sin \omega^{t}=0
\end{aligned}
$$




\section{MODEL TESTS ON THE MOTION OF MOORED SHIPS PLACED ON LONG WAVES}

Provided the mooring restraint law has a continuous slope and is symmetrical (as it is for the mooring represented in equation (3)), and $n \neq 1$, the ship motion will be periodic with the same period as the exciting force, and symmetrical, but not purely harmonic, i.e. it will contain harmonic components of period $2 \pi$ and integral multiples. The above statement is from reference $14, \bar{\omega}$ page 355 . Similarly, if the restraint law has a continuous slope, but is unsymmetrical, the motion will be periodic, but unsymmetrical. The present experiments have shown that if the restraint equation contains discontinuities of gradient, as it does for an actual ship mooring, the transient motions are repeatediy generated and there is no certainty that the motion will be periodic or symmetrical even if the moorings are symmetrical. This latter case prevails at full scale and the author considers this explains the erratic motion of ships at typical moorings even when the exciting waves are regular.

Reverting to equation (3), two procedures are available for a solution: a step by step analysis (requiring numerical values for $K, M$, $n, x_{0}$ and $\left.\omega\right)$ will give an accurate solution for ship displacement, $s$. Alternatively, an approximate solution may be obtained by ignoring the harmonics other than the fundamental. The second method has the advantage that the symbols may be retained, permitting a Ereater generality of discussion. However, the first method allows the amplitudes of the higher harmonics to be measurec. Joosting 5 analysed these harmonics and concluded that the significant component only reached a magnitude of $8 \%$ of the fundamental even for values of $\mathrm{n}$ as high as 7. This implies the approximate solution will be correct to at least the same order of accuracy

Thus we assume,

$$
s=s_{0} \sin \text { at }\left(s_{0}+\text { ve or }-v e\right)
$$

No phase angle is required as the first two terms of equation (3) differ in phase by $180^{\circ}$; thus the possible phase differences for $\mathrm{s}$ are only $180^{\circ}$ or $0^{\circ}$, and these can be allowed for by the alternative signs for $s_{0}$. $s_{o}$ positive means the ship and water motions are in opposition; $s_{0}$ negative means they are in phase.

Inserting the value of $s$ in equation (3) we have $-\omega^{2} s_{0} \sin \omega t+\frac{K}{M} s_{0} n(\sin \omega t)^{n}-x_{0} \omega^{2} \sin \omega t=0$

or

$$
\frac{K}{M \omega^{2}} s_{0}^{n}(\sin \omega t)^{n-1}=x_{0}+s_{0}
$$

This relation is not identically true because of the time dependent term ( $\sin (\mathrm{t}))^{\mathrm{n}}-1$

$$
\begin{aligned}
& \quad \text { But } 0<\frac{\omega}{2 \pi} \int_{0}^{\frac{2 \pi}{\omega}}(\sin a t)^{n-1}<1 \\
& \therefore \frac{K s_{0}{ }^{n}}{M \omega^{2} C_{k}}=x_{0}+s_{0} \\
& \text { where } C_{k}>1
\end{aligned}
$$


COASTAL ENGINEERING

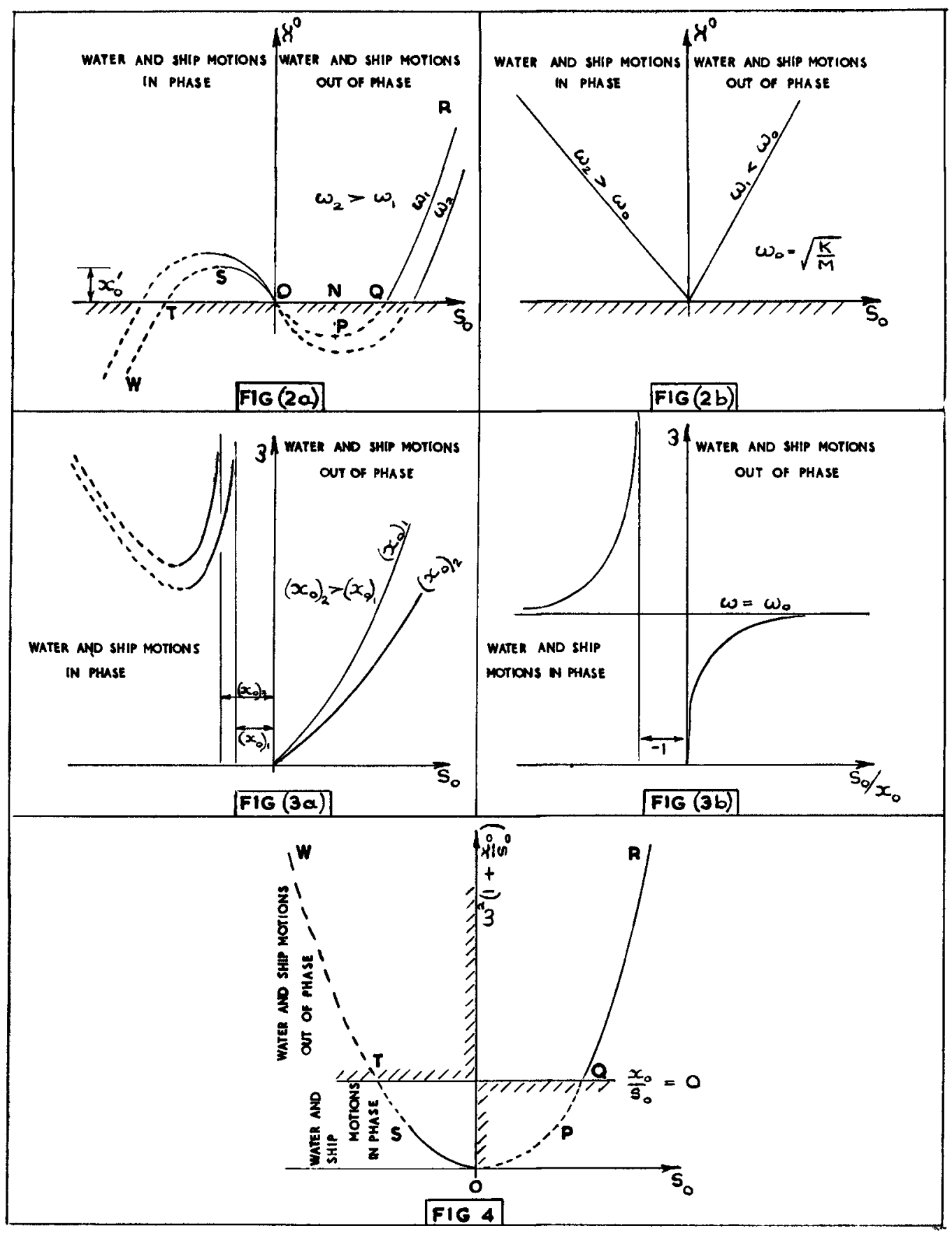

Figs. 2, 3, 4. Alternative forms of presentation for the theoretical motion of a moored ship. 


\section{MODEL TESTS ON THE MOTION \\ OF MOORED SHIPS PLACED ON LONG WAVES}

This important equation was presented independently by WiIson $^{3}$ and Joosting 5 but the above derivation is simplet. Equation (4) contains the three essential variables $s_{0}, x_{0}$ and $a$ the last two being regarded as independent. Both iilson and Joosting obtained a value

$$
c_{k}=1+0.19(n-1)
$$

by ensuring that equation (4) with $x_{0}=0$ (free, undamped motion) agrees with the exact analytical solution which happens to be available for this particular case. It does not follow that the same value of $C_{k}$ is applicable to forced vibrations.

Equation (4) can be presented graphically in several ways, most simply in Fig. (2a) where $K, M, \omega, n$ and $C_{k}$ are presumed known constants.

If $s_{O}$ is considered to depend on $x_{O}, x_{0}$ should be considered positive and then the sign of $s_{0}$ depends on the phase; thus the hatched area in Fig. (2a) is inadmissible. The curve splits into two regions $R Q$ and $O S$ (the region ST is rejecter because a slight decrease in $x_{0}$ produces an in phase increase in ship movement which is unreal). Thus we see that over a limited range of $x_{0}\left(0\right.$ to $\left.x_{0} 1\right)$ there are two modes of oscillation, one of relatively small amplitude and in phase, the other larger and out of phase. For values of $x_{0}>x_{0}{ }_{1}$, only the out of phase motion exists. If the water motion is starteo and the ship subsequently releasec, the mode followed (if an alternative exists) depends on release conditions, release at the instant of stationary water giving the in phase mode, an out of phase release with adequate displacement giving the out of phase mode. It also appears from the graph that there is a range of ship amplitudes which do not occur, in the range $O N<s_{O}<$ QQ. In addition damping effects (ignored in this analysis) will not allow the motions represented by the vicinity of point $Q$.

Fig. (4) is an alternative way of presenting the same infornation, which is more suitable for plotting experimental results particularly where double logarithmic scales are used, also w may now be included in the ordinate as an additional variable. The letters $0, P, Q$ etc. have the same significance as in Fig. (2a) and the hatching indicates negative values of $x_{0}$; thus the real zones are $Q R$ and $O S$. However, $O S$ and $O P$ are mirror images in the vertical axis, so with the convention that in phase values are regarded as $x_{0}$ negative, so positive, the complete motion may be represented by OPR which is a straight line if double logarithmic scales are used.

Fig. (3a) is a further alternative presentation of the equation, and Figs. (2b) and ( $3 \mathrm{~b}$ ) are both drawn for the particular case of $n=1$, i.e. linear springs with no free play. Comparisons between Figs. (3a) and (3b) emphasize the difference between the motions due to linear and non-linear spring characteristics. If $n=1$, there are no ambictous motions, a particular value of $\omega$ causes a unique value of $s_{0}$ for any particular value of $x_{0}$, and moreover doubling $x_{0}$ will double $s_{0}$. In addition, resonance is possible where the applied frequency is equal to the natural frequency, which results in an infinite ship amplitude in the absence of damping. By contrast when $\mathrm{n} \neq 1$, alternative motions 


\section{COASTAL ENGINEERING}

Table 1

The variation of virtual mass with water depth, $m I=135 \mathrm{lbs}$.

\begin{tabular}{|c|c|c|c|c|c|c|}
\hline $\begin{array}{l}\text { Type of } \\
\text { motion }\end{array}$ & $\begin{array}{l}\text { Spring } \\
\text { Stiffness }\end{array}$ & $\begin{array}{l}\text { Water } \\
\text { Depth }\end{array}$ & $\begin{array}{l}\text { Period } \\
\text { Secs }\end{array}$ & $\begin{array}{c}M= \\
m_{1}+m_{2}\end{array}$ & $\mathrm{~m}_{2}$ & $\frac{\mathrm{m}_{2}}{\mathrm{~m}_{1}}$ \\
\hline Transverse & $0.81 \mathrm{bs} / \mathrm{in}$ & $8.2^{\prime \prime}$ & 8.24 & 526 & 391 & 2.89 \\
\hline$n$ & " & 7.2 & 9.34 & 675 & 540 & 4.00 \\
\hline$n$ & $n$ & 9.5 & 7.69 & 454 & 319 & 2.36 \\
\hline$n$ & $*$ & 10.7 & 7.4 & 424 & 289 & 2.14 \\
\hline$n$ & $0.61 \mathrm{bs} / \mathrm{in}$ & 10.7 & 8.62 & 432 & 297 & 2.20 \\
\hline $\begin{array}{l}\text { Longitu- } \\
\text { dinal }\end{array}$ & $0.8 \mathrm{Ibs} / \mathrm{in}$ & 6.2 & 4.35 & 148 & 13 & 0.09 \\
\hline$"$ & " & 7.2 & 4.38 & 150 & 15 & 0.11 \\
\hline$n$ & $n$ & 8.2 & 4.36 & 148.5 & 13.5 & 0.10 \\
\hline$n$ & $n$ & 10.0 & 4.33 & 146 & 11.0 & 0.08 \\
\hline
\end{tabular}

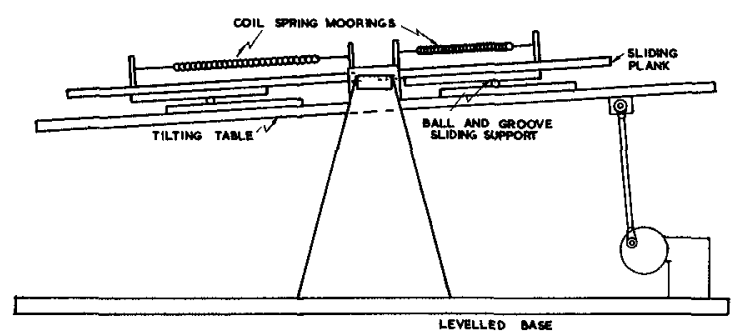

Fig. 5. A mechanical analogy to wave action on ships, showing a tilting table moving a "moored" plank.

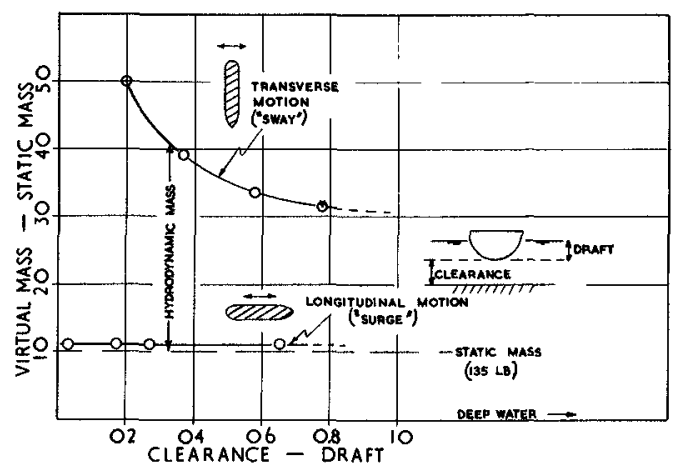

Fig. 6. The influence of water dept on the virtual mass of model ships i sway or surge motion. 


\section{MODEL TESTS ON THE MOTION \\ OF MOORED SHIPS PLACED ON LONG WAVES}

exist as pointed out in an earlier paragraph, doubling $x_{0}$ does not double $s_{0}$, and all ship amplitudes are finite even in the absence of damping.

\section{APPARATUS}

The model tests were carried out in a flume of rectangular crosssection, of width $5 \mathrm{ft}$, length $29 \mathrm{ft}$, maximum water depth 10 inches. Filters were placed at each end of the effective working section which was $15 \mathrm{ft}$ long. There was a sump at each end of the flume to which a pump system was connected in such a way that water colild be transferred from one sump to the other, in either direction. The butterfly valve controlling the flow direction could be rotated mechanically in a uniform manner thus producing a water oscillation in the flume, equivalent to a stationary wave with a node at the centre line. A surface float in the nodal region was photographed and the displacement time curve obtained. This confirmed that the motion was essentially sinusoidal. The range of wave period available was from 25 secs. to 2.7 secs.

The model ship used in the experiment was $80 \mathrm{in.}$ long, with a beam of $10 \mathrm{in.,}$ a draught of $6 \mathrm{in}$. and weighed $135 \mathrm{lbs}$. It was symmetrical and was moored with its centre at the nodal point. The moorings consisted of rings of thin sheet metal which formed the spring element and were rigidly attached to the ship, one at each end. The free ends of the springs were fastened to light inelastic chains which in turn were fixed to stiff cantilever bars, the cantilevers forming the mooring anchorages at the quay side. By judicious variation of ring diameter, strip thickness and width, an appreciable range of spring stiffness could be obtained although in most cases the linear range of the spring was exceeded.

The mooring forces were measured either by visual estimation of ship displacement and subsequent reference to a spring calibration curve; or by placing electric strain gauges on the spring anchorage strips and recording the strains on a pen recorder chart. In the latter case, a calibration was obtained from a static load test. The spring stiffness largely dictated the method of measurement, the extension of the stiffer springs was too small and rapid to be observed visually.

The water displacement, $s_{0}$, was found by observing the movement of small floats in the vicinity of the node.

Fig. (5) shows a mechanical analogy to wave action on ships which was intended as an attractive way of demonstrating in a simple manner some of the complexities of the motions of moored ships. A pivoted table is tilted harmonically by a motor driven crank, and a plank is supported on the table on three steel balls which run in grooves in such a way as to allow the plank to move up or down the table. The plank is restrained by two equal springs of suitable stiffness which provide in effect a symmetrical "mooring" system. The plank is analogous to the ship, and the table represents the wave surface in the 
COASTAL ENGINEERING
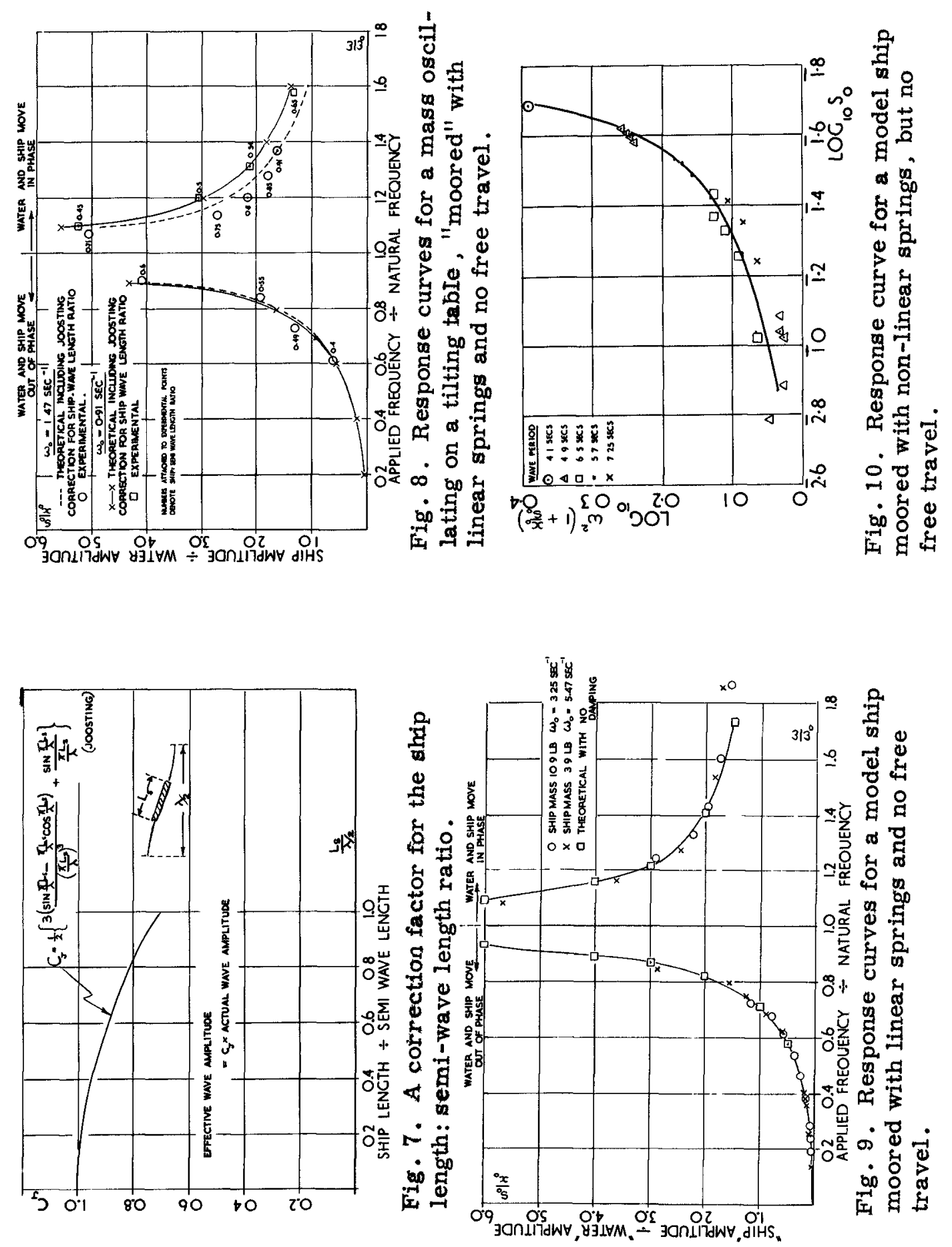


\section{MODEL TESTS ON THE MOTION OF MOORED SHIPS PLACED ON LONG WAVES}

nodal region, the nodal point being at the pivot. Some measurements were made on the analogy and are reported in the next section.

\section{EXPERTMENTAL RESULTS}

As a preliminary to the wave tests, the irtual mass of the ship was found by the free oscillation method described in the paragraphs headed THEORI. The two springs used were of the coil type with a linear spring law, $K=0.4 \mathrm{lbs} / \mathrm{in}$. One spring was attached to each end of the ship and pretensioned to prevent either spring slackening in the subsequent free oscillation. Although not specifically required for these tests, the virtual mass for transverse oscillation was found in the same way. The water depth was also varied, to investigate the Influence of the flume bed on the ship motion, and in one case different springs were used. This set of results is tabulated in Table $I$ and graphea in Fig. (6).

The wave experiments divided into three sets. Set. No.1 used both the mechanical analogy and the wave flume and in this set, the springs used were of the linear law type, with no free play. This is the only case for which the equation of motion can be solved exactly, and thus a direct comparison between theory and experiment was possible. The tests were intended to check the validity of the equation of motion formulated in an earlier section; to check the soundness of the assumption that damping had a negligible influence; and to consider the correction factor to allow for a finite ship length to wave length ratio. A correction for this latter effect has been proposed by Joosting ${ }^{5}$ and is shown graphically in Fig. (7). The mechanical analogy uses a mass effectively concentrated at the nodal point and no correction factor is required. An additional outcome of these tests was the extent to which the mechanical analogy was valid. The natural period for the ship was varied by using two different pairs of springs, that of the analogy by varying the plank mass. The water amplitude and frequency were independent variables for the ship flume, for the analogy the frequency was also variable, but the maximum "water" slope was constant. The results of set No.1 are shown in Figs. (8) and (9).

The second set of tests (set $\Uparrow 0.2$ ) used symmetrical non-linear springs without free play and these were carried out on the ship model only. These were intended to reveal the two alternative modes of motion for certain wave conditions and also to verify the author's contention that non-linearity in a mooring characteristic will not in itself produce irregular or unsymmetrical motions. Both the water period and amplitude were varied, and according to the analysis presented in an earlier paragraph, one set of results, including variation of both $x_{0}$ and $\omega$, should plot as a straight line (using the appropriate double logarithmic co-ordinates) provided the spring restraint approximates to a power law characteristic. The validity of the analysis may be checked by the extent to which sets of experimental points lie on straight lines, and in addition the slope and intercept of the best fitted line give values for $n$ and $K$ which may be compared with the 
behaviour of the spring which was actually used. The $n$ and $K$ values are found, in fact, from the equation (4) written in the form

$$
\log _{10} \omega^{2}\left(1+\frac{x_{0}}{s_{0}}\right)=\log _{10} \frac{K}{m c_{k}}+(n-1) \log _{10} s_{0}
$$

The results of set No.2 were plotted in the form indicated in Fig.4, the actual graph being Fig. (10).

In the final tests (set No.3) the nearest approach to prototype conditions was reached, with non-linear moorings and some free play. It was required to verify that this discontinuous type of mooring could be effectively represented by a power law restraint as proposed by Wilson'. The results are presented in Figs. (11) to (16), two values of free travel being combined with various springs and subjected to various wave conditions. The values of spring stiffness given are to be taken as correct at the displacement mentioned i.e. a $0.1 \mathrm{in} / \mathrm{lb}$ spring means that a $1 \mathrm{lb}$ force will extend the spring by $0.1 \mathrm{in.}$, although for extensions above or below this value, the force will not be changed proportionally due to the non-linearity of the spring law. Against the straight lines of Figs. (11b) to $(16 \mathrm{~b})$ is given the value of $\mathrm{K} / \mathrm{C}_{k}$ and $n$ found from the equation of the line (being the best fit to the experimental points). These values are obtained from equation (5). In Figs. (11a) to (16a) are shown both the actual spring extension curve, and the curve deduced from the values of $k$ and $n$, taking $C_{k}$ values from the Wilson-Joosting expression

$$
c_{k}=1+0.19(n-1)
$$

\section{DISCUSSION}

Considering the virtual mass results first (Fig. (6)) the range of values of hydrodynamic mass for longitudinal ship motion ( $8 \%$ to $12 \%$ of the displaced mass) agrees with some unpublished results obtained at Cape Town University where values of $8 \%$ to $10 \%$ were found for both constant and harmonic accelerations of typical ship models. These values agree indirectly with field measurements as coefficients of this magnitude might well be overlooked where coupled motions are present, and this has led to the conclusion by $0^{\prime B r i e n}$ and Kuchenreuther ${ }^{8}$ that the influence is negligible. The proximity of the channel bed appears to be unimportant for longitudinal oscillations.

The values of hydrodynamic mass for transverse motion (in the range $200 \%$ to $400 \%$ of the displaced mass) are higher than previously contemplated and require discussion. In these oscillations, care was taken to ensure that the motions were purely transverse, and that pitch and roll motions were virtually absent. The decay of amplitude was noted and an estimate made of the damping force, assumed to be proportional to velocity for this purpose. This indicated that the influence of damping on the free period was negligible. Reference (8) concluded that the sway hydrodynamic mass was negligible and this led to a consideration of ship proportions. 
MODEL TESTS ON THE MOTION

OF MOORED SHIPS PLACED ON LONG WAVES

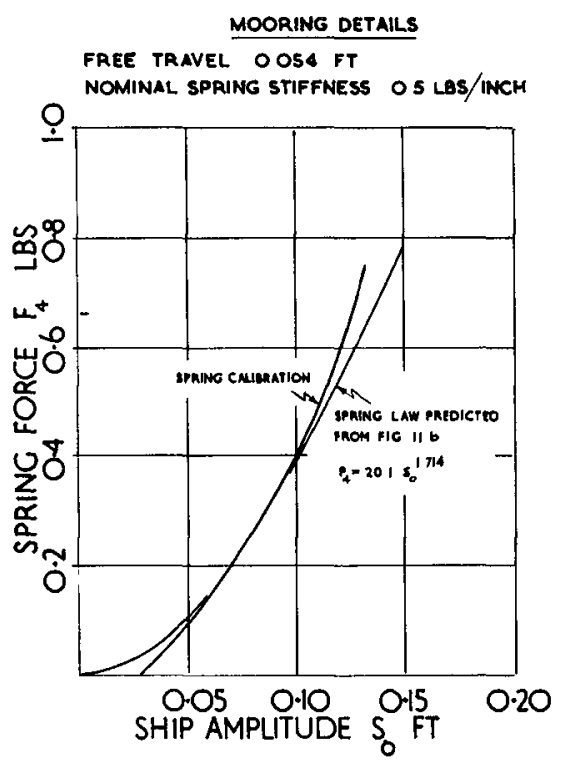

a

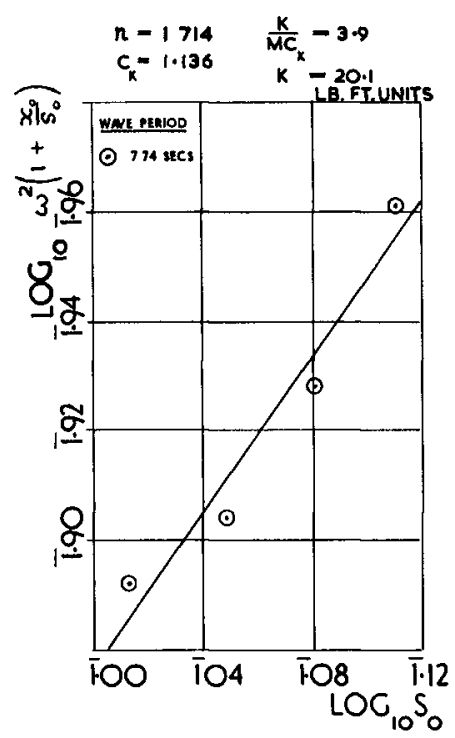

b

Fig. 11. Spring laws and response curves for ships moored with non-linear springs and free travel.

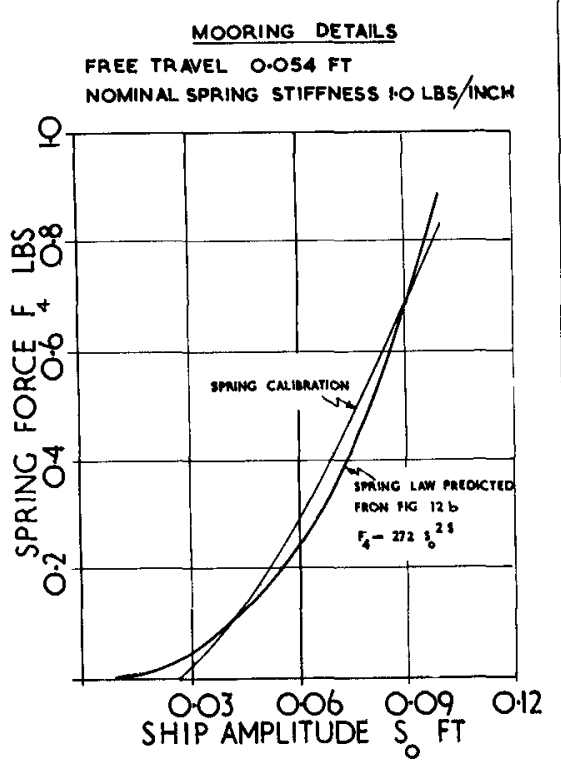

a

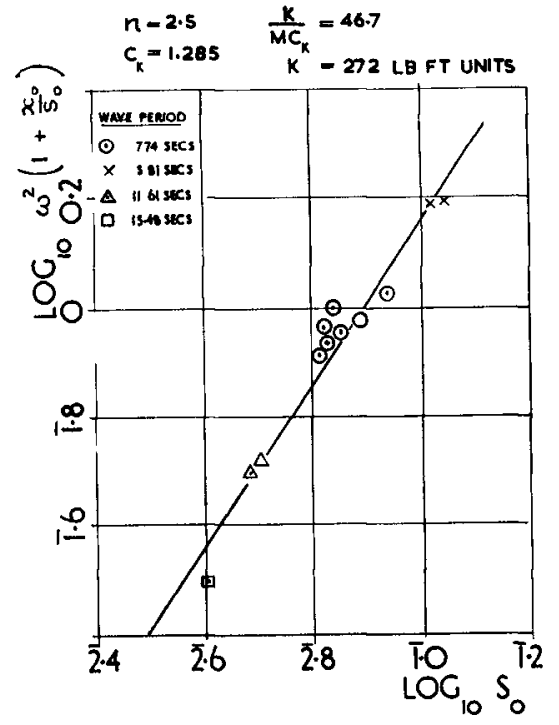

b

Fig. 12. Spring laws and response curves for ships moored with non-linear springs and free travel. 

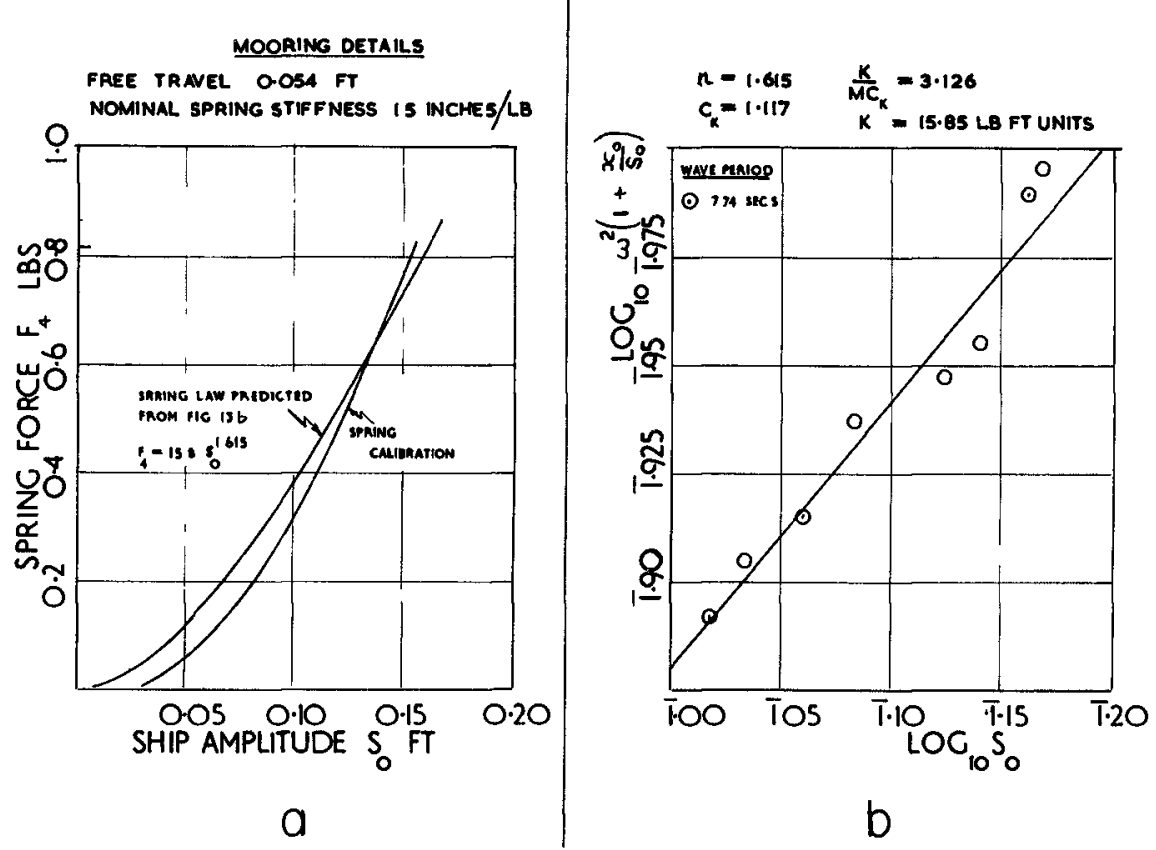

Fig. 13. Spring laws and response curves for ships moored with non-linear springs and free travel.
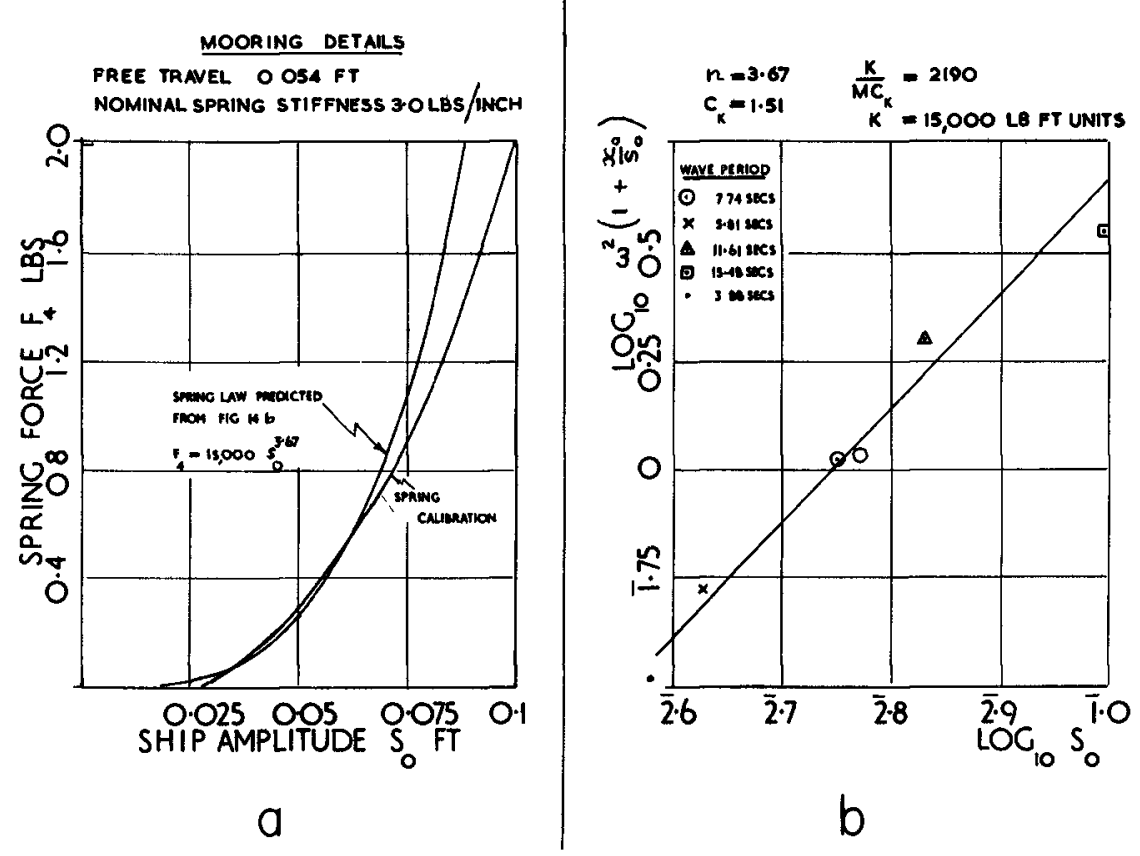

Fig. 14. Spring laws and response curves for ships moored with non-linear springs and free travel. 
MODEL T'ESTS ON THE MOTION

OF MOORED SHIPS PLACED ON LONG WAVES

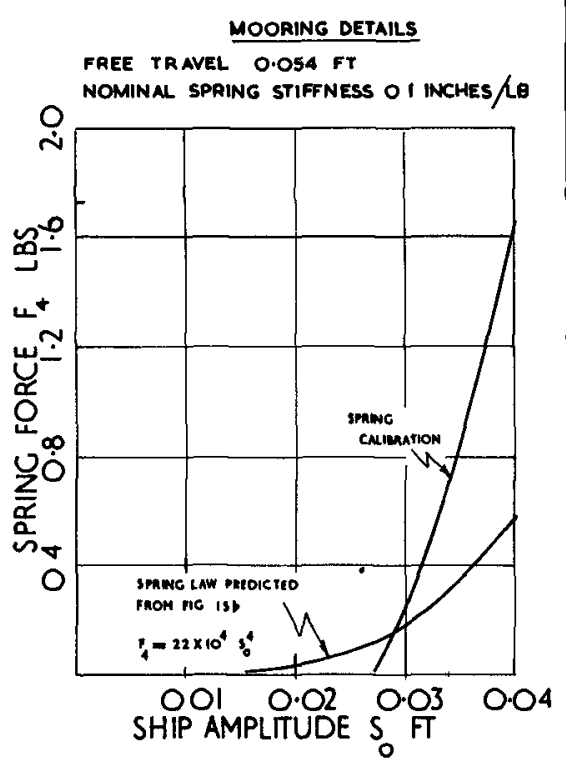

a

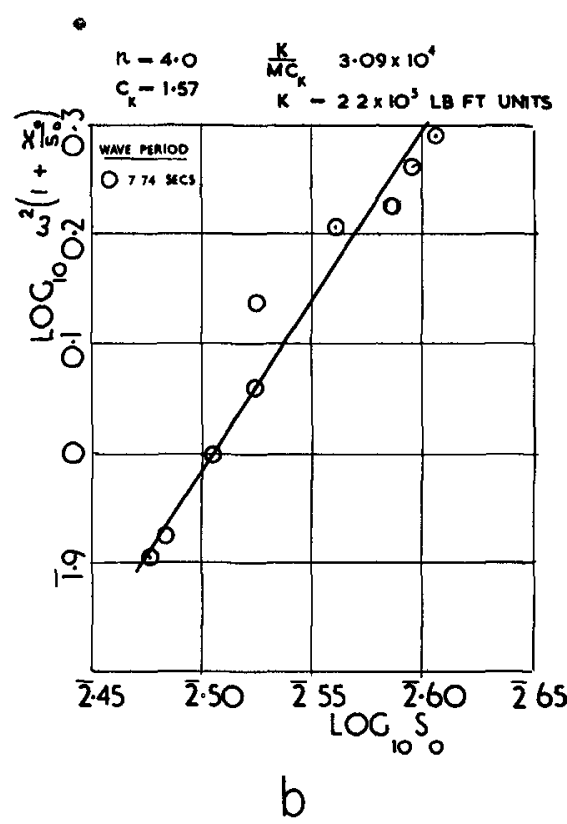

Fig. 15. Spring laws and response curves for ships moored with non-linear springs and free travel.
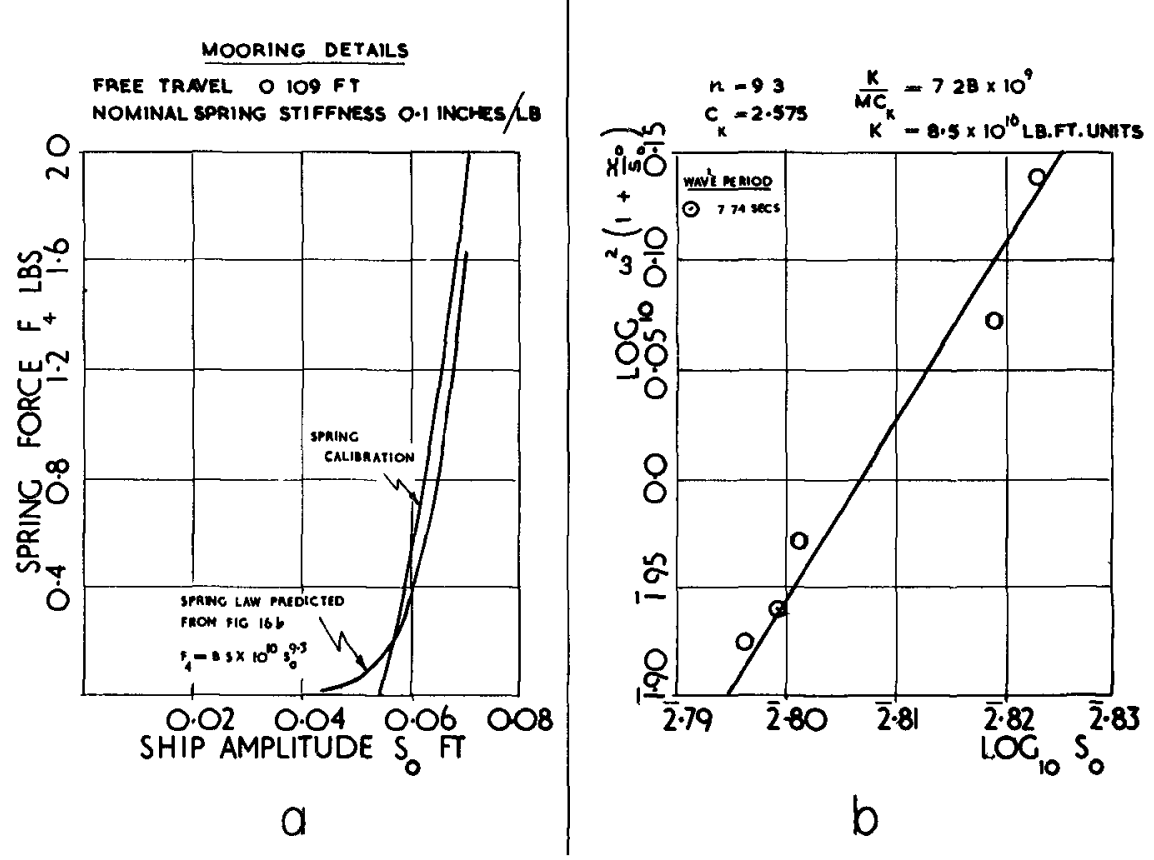

Fig. 16. Spring laws and response curves for ships moored with non-linear springs and free travel. 


\section{COASTAL ENGINEERING}

Wilson ${ }^{13}$ presents proportions for a wide range of ship forms, which indicate that the draft:beam ratio lies between 0.35 and 0.5 , and the length:beam ratio lies between 5 and 6.5. The values for the ship model used in the present paper are 0.6 and 8.0 respectively, the values for the dock in reference (8) are 0.12 and 4 respectively. The draft:beam ratio is the dominant one and a factor of 5 between the ratios for the two vessels under comparison may well explain the differing conclisions. Some theoretical evidence is available in reference (12), where virtual masses for long rectangular blocks are given for various araft:beam ratios, the theory being valid for an infinite inviscid fluid. If it is assumed that the same coefficients are applicable to a floating block of half the draft, an estimate can be made of the added masses for floating ships. These values indicate that the added mass, when expressed as a fraction of the displaced mass, is closely proportional to the draft:beam ratio and allowing for the fact that the dock is possibly not long enough for end effects to be negligible, the author's conclusions are not in such direct conflict with those of $\mathrm{O}^{\prime B r i e n}$ and Kuchenreuther as at first sight appear. Perhaps the most surprising fact which emerges is the sharp increase of the sway added mass in shallow water, as the clearance to draft ratios covered in Fig. (6) are typical of those encountered in many ship fendering problems.

The results of the first set of tests (linear springs with no free play) are shown in Figs. (8) and (9) for the ship and the analogy respectively. The agreement in Fig. (8) between theory and experiment is close for frequencies below the natural frequency, but for frequencies greater than this, discrepancies are apparent. The discrepancies are most conspicuous for ship:semi-wave length ratios greater than 0.6 and the conclusion drawn is that the influence of this ratio is greater than the correction factor presented by Joosting 5 (Fig. (7)) would indicate. The influence of damping on the response curve was estimated but found to be small. The agreement in Fig. (9) was close which showed that the mechanical damping was of the same order as the fluid damping on the ship. The inter-agreement of Figs. (8) and (9) with theory shows that the equation of motion is correctly formulated, and that the mechanical analogy to wave motion on the ship is sound.

For tests in set No.2 (Fig. (10)) the curve shown is the sketched best fit to the experimental data and it is clear that the slope of the line varies, being flat at low ship amplitude and steepening with increasing ship movements. Thus according to eqn. (5) the spring is linear $(n=1)$ for small values of $s_{0}$, the $n$ value increasing as $s_{0}$ increases. This in fact describes the actual behaviour of the metal ring mooring used, although due to the curvature of the line in Fig. (10) no attempt was made in this case to deduce the spring law. These tests also confirmed that alternative modes of oscillation (one in phase, one out of phase) were possible for certain wave conaitions, however, in no case did the ship oscillate in any way other than a periodic and symmetrical manner. The ship period always coincided with the wave period, and this confirmed that free travel (or some other discontinuity in the mooring characteristic) is necessary in order to obtain irregular impacts. 


\section{MODEL TESTS ON THE MOTION \\ OF MOORED SHIPS PLACED ON LONG WAVES}

On examining the experimental results from set No.3, it was found that some readings offered no difficulty in interpretation; the model ship tensioned the moorings at each end alternately, at intervals close to half the exciting period and with approximately equal force. In such a case the mean force was found and the corresponding amplitude of ship motion taken as so. In other cases, however, the motion was unsymmetrical, two or more impacts at one mooring occuring between consecutive impacts at the other, the magnitude of the multiple bumps being in general less than the single one. The average of the single impact values was considered the appropriate force in these cases. Some pen deflection records illustrating these asymmetrical motions are shown in Fig. (17). As this investigation was started with a view to obtaining peak mooring forces, ship motions of in phase type with small amplitude were not examined in detail, although some experimental values were recorded. In addition, no in-phase motions with a ship amplitude less than the semi-free travel could be investigated as the moorings were not tensioned under these conditions.

Considering Figs. (11b) to (16b) the experimental points show scatter, but the general trend is linear and the averaging process described in an earlier paragraph no doubt explains some of the deviations. The agreement of actual and deduced spring characteristics in Figs. (11a) to (16a) is fair when it is considered that the analysis deals with a continuous power law curve for spring action, whereas the actual restraints are not smooth. Perhaps more important the agreement between theory and experiment is sufficiently encouraging to suggest that future experiments on ship oscillations should be planned and presented in a similar manner.

\section{APPLICATION TO PROTOTYPE SHIPS}

Accepting the conclusion that a ship mooring may be represented by a power law characteristic, it remains to consider the application to full scale ships at typical moorings.

It will be noticed that the co-ordinates in Figs. (11b) to (16b) are kinematic, however, the values of $s_{0}$ will be higher and those of $\omega^{2}\left(1+\frac{x_{0}}{S_{0}}\right)$ will be lower for full size ships than for the small models used here.

However, the model moorings were idealised to lie along the longitudinal axis of the ship and the ship was remote from the quay, whereas in the prototype the moorings are oblique, coupled motions will develop, and impacts between the ship and the quay are inevitable. It is believed that the simple analysis will be applicable to ships ranging at quays where the direction of the ship and the wave motion is parallel to the quayside (the waves being either stationary due to harbour resonances or long swell waves) and the transverse motion is of secondary importance. In fact the transverse impacts reduce the ship energy and it is probable 

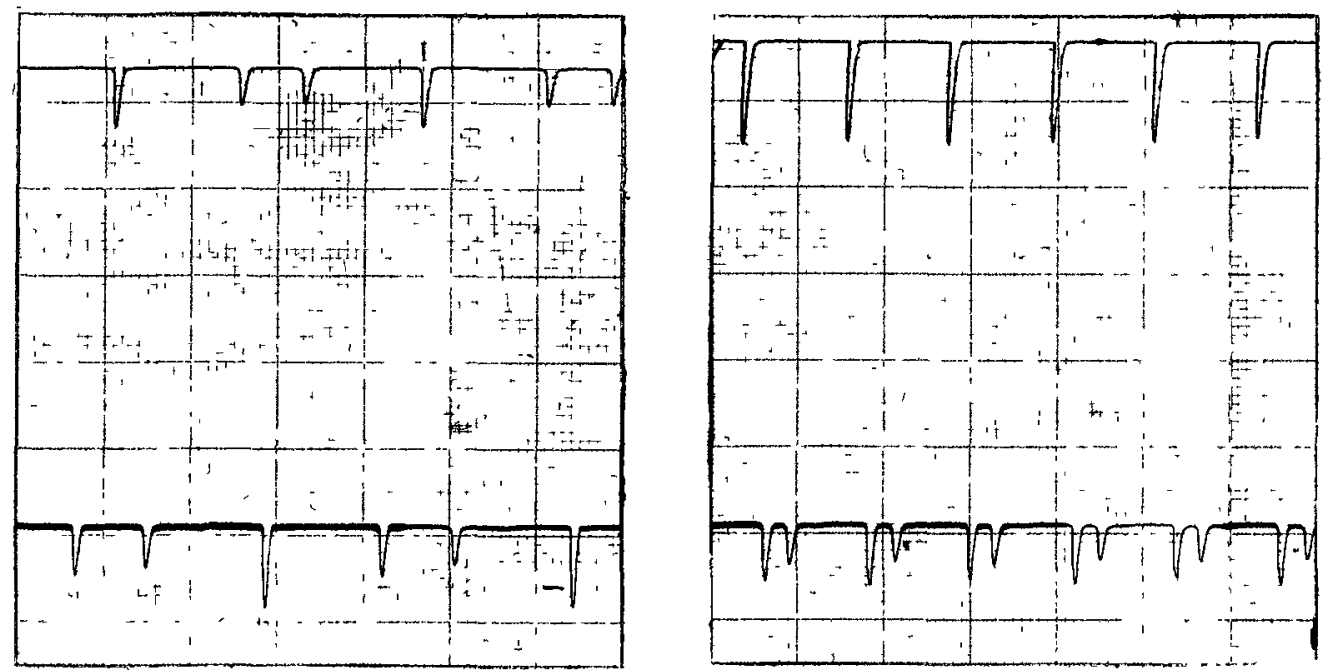

Fig. 17a. Water amplitude $=0.05 \mathrm{ft}$
Ship motion symmetrical, but repeats every two wave periods.

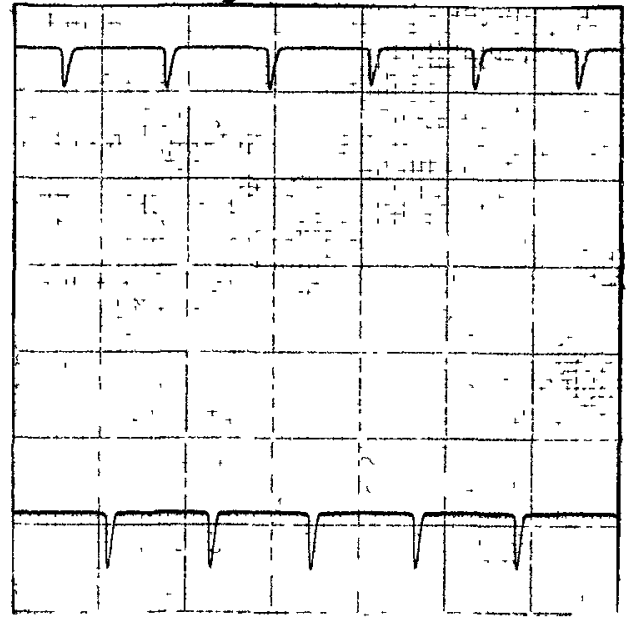

Fig.17b. Water amplitude $=0.12 \mathrm{ft}$ Ship motion asymmetrical, two impacts at one end, one impact at the other.

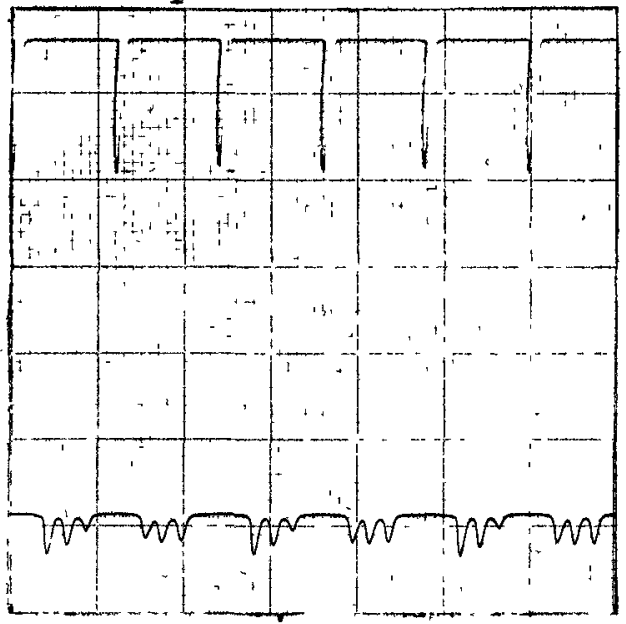

Fig.17c. Water amplitude $=0.16 \mathrm{ft}$ Ship motion symmetrical

Fig.17d. Water amplitude $=0.16 \mathrm{ft}$ Ship motion asymmetrical. three impacts at one end one impact at the other.

The motion in Figs. $17 \mathrm{c} \& 17 \mathrm{~d}$ depends on the release conditions.

Fig. 17: Pen records of mooring impacts at each end of a model ship.

Mooring details: Free travel $0.054 \mathrm{ft}$ Nominal spring stiffness 0.1 inches $/ 1$ b. Wave period 7.74 secs. 


\section{MODEL TESTS ON THE MOTION OF MOORED SHIPS PLACED ON LONG WAVES}

that calculations based only on surge motion are pessimistic. The alternative motions which may occur for certain water amplitudes do not offer any difficulty as the assumption will always have to be made that the ship will adopt the out of phase mode as this is the worst case for the moorings.

To use a graph such as Fig. (11b) for prototype force prediction, the straight line is drawn which represents a close fitting power law characteristic to the actual mooring to be used at either end of the ship (see equation 5). For any wave periodicity the motion of the ship $\left(\mathbf{s}_{0}\right)$ can be calculated for a particular water amplitude $\left(x_{0}\right)$ and frequency (w) by a trial and error method, only out of phase motions being of interest. The ship motion leads directly to the mooring forces via a calibration curve for the mooring stiffness.

A general deduction may be made for severe motions where the ship may move considerably more than the water.

$$
\begin{aligned}
& \text { Let } s_{0}=p x_{0}, \quad p \gg 1 \\
& \text { Then } 1+\frac{x_{0}}{s_{0}} \doteq 1 \\
& \therefore K s_{0}{ }^{n}=M \omega R C_{k} s_{O}=M x_{0} \omega^{R} C_{k} \cdot p \cdot
\end{aligned}
$$

Therefore the peak mooring force is rather more than $p$ times the force required to hold the ship stationary. It appears, that for a given water amplitude, the force increases as the wave period decreases, but a limit is reached when the wave length becomes appreciably less than twice the ship length.

\section{MODEI SCAIES}

The experiments described in this paper are really tests on small scale ships with a view to understanding the problems involved, rather than model tests on a particular ship. However, any ship and mooring combination may be considered as a model of some larger ship with the following scales:-

Length scale $I: 1$, applicable to ship, water and mooring geometries.

Mass or Force scale $I^{3}: 1$, applicable to ship mass, mooring forces.

Velocity scale $\quad V_{I}: 1$, applicable to wave or ship speed.

Frequency scale $1: \sqrt{I}$, applicable to wave or ship frequency.

Spring factor $K \quad L^{3-n}: 1$

$\mathrm{n}, \mathrm{C}_{\mathrm{k}}$ $1: 1$

writing the eqn. (4) in the form

$$
\frac{k L^{n-1}}{M \omega R C_{k}}=1+\frac{\infty_{0}^{*}}{s_{0}^{*}} \frac{1}{\left(s_{0}^{*}\right)^{n-1}}
$$




\section{COASTAL ENGINEERING}

where $s_{0}^{*}=s_{0} / \mathrm{L} \& x_{0}^{*}=x_{0} / \mathrm{L}$

and using the scales in the form given above, the left hand side of equation (6) is independent of the scale, which confirms the similarity of the model and prototype motions.

\section{CONCLUSTONS}

(a) The hydrodynamic mass for a ship moving longitudinally is approximately one tenth of its displaced mass and shows only a slight tendency to increase in very shallow water. The hyarodynanic mass for a ship moving transversely is of the same order as the displaced mass in deep water, and may be several times as great for shallow water where the keel clearance is less than about half the draft.

(b) The equation of motion as presented in this paper-was confirmed by tests with linear springs for which an exact analysis is possible. The assumption of zero damping for most practical cases is justified.

(c) The mechanical analogy is shown to be a replica of wave motion on ships, and the author considers that it could be used profitably as an alternative to a wave flume for problems of the ship mooring type.

(d) A mooring having a non-linear spring characteristic without discontinuities of gradient verified several details of theory, such as alternative ship motions for certain wave conditions, and symmetrical moorings producing only symmetrical ship movements.

(e) It was verified that a typical ship mooring, having both non-linear and free travel components, could be approximated by a power law characteristic in order to predict the average mooring forces. In some cases, however, the motion would become asymmetrical with small multiple impacts at one end. These unsymmetrical ship motions are not predictable, except that for a given free travel, they appear more likely to occur with stiff moorings than soft.

(f) Methods are given for predicting the forces on a prototype ship in surge motion, either analytically or by model scaling.

\section{ACTNOYILETGEISANS}

The author wishes to acknowledge the giidance and assistance of Mr. R.C.H. Russell, Senior Principal Scientific Officer of the Iydratilics Research Station, who designed the equipment and under whose direct supervision the experimental results of set No. 3 were obtained.

\section{REFERENCES}

1. Wilson B.W., Ship response to range action in harbour basins. Trans.A.S.C.E. Hol. 116, p.1129, 1951. 


\section{MODEL TESTS ON THE MOTION \\ OF MOORED SHIPS PLACED ON LONG WAVES}

2. Knapp R.T., Wave produced motion of moored ships. Proceedings of the second conference on Coastal engineering 1952, p.48.

3. Abramson H.N., Wilson B.W., A further analysis of the longitudinal response of moored vessels to sea oscillations. Proceedings of the 2nd Mid-Western Conference on Solid Mechanics, Purdue University, Pugdue, September 1955, p. 236.

4. Deacon G.E.R., Russell R.C.H., Palmer J.E.G., Paper, Section II, Communication 1. Proceedings of the 19th International Navigation Congress, London, 1957, p.75.

5. Joosting N.C.Q., Paper, Section II, Comunication 1. Proceedings of the 19th International Navigation Congress, London, 1957, p. 205.

6. Wiegel R.I., Clough R.A., Dilley R.A., Williams T.B., Model study of floating ary dock mooring forces, Proceedings of the symposium on the behaviour of ships in a seaway. September,1957, Wageningen, Netherlands.

7. Wiegel R.I., Beebe K.E., Dilley R.A., Model studies of the dynamics of an LSM moored in waves. Proceeoings of the 6 th Conference on Coastal engineering, December, 1957.

8. O'Brien J.T., Kuchenreuther D.J., Free oscillation in surge and sway of a moored floating dry dock. Proceedings on the 6 th Conference on Coastal engineering, December, 1957.

9. O'Brien J.T., Kuchenreuther D.J., Proc. A.S.C.E. Journal of the

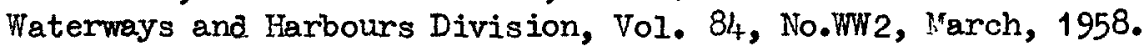
Paper 1571.

10. Russell R.C.H., A study of the movement of moored ships subjected to wave action. Proc. I.C.E. Vol. 12, April 1959, p. 379.

11. Wiegel R.I., Dilley R.A., Williams J.B., Model study of mooring forces of a dockec. ship. Proc. A.S.C.E. Journal of the ivaterways and Harbours Division, Vol. 85, No.WW2, June 1959, Paper No.2071.

12. Browne A.D., Mouillin E.B., Perkins A.J., The added masses of prisms floating in water Proc. Camb.Phil. Soc. Vol.26, 1929/30.

13. Wilson B.W., The energy problem in the mooring of ships exposed to waves. Princeton University Conference on berthing and cargo handling in exposed locations, October, 1958.

14. Inglis C., Applied mechanics for engineers. Cambridge University press, 1951 . 